\title{
Grifola frondosa polysaccharides induce breast cancer cell apoptosis via the mitochondrial-dependent apoptotic pathway
}

\author{
YIZHI ZHANG ${ }^{1,2}$, DEJUN SUN ${ }^{2}$, QINGJIN MENG $^{3}$, WANXU GUO $^{1}$, QIUHUI CHEN $^{1}$ and YING ZHANG ${ }^{1}$ \\ ${ }^{1}$ Department of Neurology, The Second Hospital of Jilin University, Jilin University, Changchun, Jilin 130041; \\ ${ }^{2}$ Department of Biomedicine, Institute for Regeneration Medicine, Jilin University, Changchun, Jilin 130021; \\ ${ }^{3}$ Department of Neurology, Brain Hospital of Jilin Province, Siping, Jilin 136000, P.R. China
}

Received January 29, 2016; Accepted July 4, 2017

DOI: $10.3892 /$ ijmm.2017.3081

\begin{abstract}
Grifola frondosa, a type of food and medical fungus, has been shown to exhibit various pharmacological activities, including anticancer effects. As the most typical cancer diagnosed among female patients, breast cancer remains a huge concern threatening human health globally. In the present study, the anti-breast cancer effects of Grifola frondosa polysaccharides (GFPs) and the underlying mechanisms were investigated in MCF-7 and MDA-MB-231 cells, as well as in nude mice bearing MCF-7 tumor xenografts. GFPs exerted cytotoxic effects on the cells, as indicated by a decrease in cell viability, and an increase in the apoptototic rate, lactate dehydrogenase release and reactive oxygen species accumulation, inducing mitochondrial dysfunction. The increased expression of Bax, cleaved caspase- 3 and caspase- 8 , and the reduced levels of B-cell lymphoma 2 (Bcl-2) and Bcl-extra large (Bcl-xL) were observed in the cells incubated with GFPs and in the tumor tissues of the mice treated with GFPs. Moreover, the GFPs significantly suppressed the phosphorylation of AKT/glycogen synthase kinase- $3 \beta$ and extracellular signal-regulated kinases in a time-dependent manner. Finally, the inhibition of MCF-7 tumor xenograft growth further confirmed the anti-breast cancer effects of GFPs. All these findings revealed that GFPs induced human breast cancer cell apoptosis via the mitochondrial-dependent apoptotic pathway, and provide experimental evidence to support the use of Grifola frondosa as a potential treatment for breast cancer.
\end{abstract}

Correspondence to: Professor Dejun Sun, Department of Biomedicine, Institute for Regeneration Medicine, Jilin University, Changchun, Jilin 130021, P.R. China

E-mail: sundjj1@126.com

Professor Ying Zhang, Department of Neurology, The Second Hospital of Jilin University, 218 Ziqiang Road, Changchun, Jilin 130041, P.R. China

E-mail: m13843440197@163.com

Key words: Grifola frondosa, polysaccharides, breast cancer, apoptosis, mitochondria

\section{Introduction}

According to the statistics, almost a quarter of female patients suffering from cancer are diagnosed with breast cancer (1). As the most typical type of cancer affecting women, even in an era with advanced medical applications, breast cancer remains a serious concernt and a threat to human health, causing significant morbidity and mortality (2). Several subtypes of breast cancer, each requiring different therapeutic regimens, limit the treatment options. The standard treatment for breast cancer is chemotherapy and radiotherapy; however, treatment outcomes are, in the most part, discouraging for patients (3). In this scenario, it is imperative to explore different alternative therapies or medicines with low toxicicity for breast cancer treatment.

Due to the significant cytotoxic activities and less adverse effects, herbal medicines have gradually become good candidates for cancer therapy (4). It has been proven that Cordyceps militaris, a folk tonic in Asia, displays pro-apoptotic properties in cells and tumor xenografts in C57BL/6 mice via mitochondrial-related pathways $(5,6)$. As a type of food and medical fungus, Grifola frondosa has been studied for years, and amino acids, polysaccharides and amounts of trace elements have been found in its fruitbody. Since the first study on the anti-tumor effects of Grifola frondosa polysaccharide (GFP) in 1984, the structure and function of its polysaccharides have been gradually analyzed (7). Pharmacological analyses and clinical trials have demonstrated that the polysaccharideenriched extract of Grifola frondosa exhibits various activities, including anti-tumor, immunomodulatory, and blood glucose and lipid regulating effects (8-10). A chemically sulfated polysaccharide purified from Grifola frondosa has also been shown to induce HepG2 cell apoptosis via the Notch 1-NF- $\mathrm{kB}$ pathway (11). However, few studies to date have reported the pro-apoptotic activities of GFP on breast cancer cells and the underlying mechanisms.

Apoptosis, an energy-dependent process, is regulated by various signals (12). During this process, cell shrinkage, chromatin condensation and DNA damage are observed (13). Mitochondrial apoptosis occurs gradually along with the depolarization of mitochondrial transmembrane potential (MMP; $\Delta \Psi \mathrm{m})$, the abnormal expressions of B-cell lymphoma 2 (Bcl-2) family members, cytochrome $c$ (Cyto $c$ ) 
over-release and caspase- 3 activation $(14,15)$. The initiator caspase (caspase-8) controls the proteolytic maturation of caspase-3 (16). The accumulation of intracellular reactive oxygen species (ROS) is capable of inducing apoptosis by interacting with proteins related to mitochondrial dysfunction. On the other hand, the activation of AKT and extracellular signalregulated kinases (ERKs) contributes to cell proliferation and apoptosis $(17,18)$.

This study aimed to investigate the anti-breast cancer effects of GFP in in vitro and in vivo models. We found that in MCF-7 and MDA-MB-231 cells, GFP induced apoptotic cell death related to mitochondrial function. GFP also significantly suppressed the growth of MCF-7 tumor xenografts in nude mice. Our data support the possible use of Grifola frondosa as a therapeutic agent for breast cancer therapy.

\section{Materials and methods}

Preparation of polysaccharides separated from Grifola frondosa. Grifola frondosa powder (100 g) was extracted twice with 10 -fold double-distilled water (DD water) at $90^{\circ} \mathrm{C}$ for $3 \mathrm{~h}$. The protein existing in the extract was removed using Sevag reagent [v (n-butanol):v (chloroform) $=1: 4,50 \mathrm{ml}$. Polysaccharides were collected via the alcohol precipitation method with 4-fold ethanol. The content of the total polysaccharides separated from Grifola frondosa was $65.2 \pm 1.05 \mathrm{mg} / \mathrm{g}$.

Cell culture. The cell lines, MDA-MB-231 (human breast epithelial cell line; ATCC no. HTB-26) and MCF-7 (human breast carcinoma cell line; ATCC no. HTB-22), were maintained in Dulbecco's modified Eagle's medium (DMEM) medium, supplemented with a $10 \%$ fetal bovine serum (FBS), $100 \mathrm{U} / \mathrm{ml}$ penicillin and $100 \mathrm{~g} / \mathrm{ml}$ streptomycin under a humidified atmosphere containing $5 \% / 95 \%$ of $\mathrm{CO}_{2} /$ air at $37^{\circ} \mathrm{C}$. The cultured medium was refreshed every 3 days. Cell culture reagents were obtained from Invitrogen Life Technologies (Carlsbad, CA, USA).

MTT cell survival assay. The cells $(5,000$ cells/100 $\mu \mathrm{l})$ were seeded into 96-well plates and incubated with GFPs at concentrations of $25,50,100,200$ and $400 \mu \mathrm{g} / \mathrm{ml}$ for 24 or $48 \mathrm{~h}$. Subsequently, $10 \mu \mathrm{l}$ of 3-(4,5-dimethylthiazol-2-yl)-2,5-diphenyltetrazolium bromide (MTT) $(0.5 \mathrm{mg} / \mathrm{ml})$ dissolved in phosphate-buffered saline (PBS) were added to each well. Following a 4-h incubation at $37^{\circ} \mathrm{C}$ in the dark, the supernatant was aspirated, and then $100 \mu \mathrm{l}$ DMSO were added. The absorbance was measured at a wavelength of $540 \mathrm{~nm}$ using a microplate reader (Bio-Rad Laboratories, Inc., Hercules, CA, USA). Values were expressed as a percentage of those from the corresponding controls.

Analysis of lactate dehydrogenase $(L D H)$ concentration and caspase- 3 activation. The cells $\left(5 \times 10^{4}\right)$ were seeded into 6-well plates and treated with 50 and $200 \mu \mathrm{g} / \mathrm{ml}$ GFPs for $24 \mathrm{~h}$. The LDH concentration in the culture medium was detected using a LDH assay kit (Nanjing Jiancheng Bioengineering Institute, Nanjing, China) according to the manufacturer's instructions.

The treated cells were collected and lysed with radioimmunoprecipitation assay (RIPA) buffer (Sigma-Aldrich, St. Louis,
MO, USA), and the protein concentration was examined using Bio-Rad protein assays. A caspase-3 colorimetric detection kit (Enzo Life Sciences, Inc., Farmingdale, NY, USA) was applied to detect caspase-3 activation. Values were expressed as a percentage of those from the corresponding controls.

Flow cytometric analysis of cell apoptosis. The cells were seeded into 6 -well plates at $5 \times 10^{4} /$ well and treated with 50 and $200 \mu \mathrm{g} / \mathrm{ml}$ GFPs for $12 \mathrm{~h}$. The treated cells were harvested and washed with PBS 3 times, and then suspended in binding buffer containing with $5 \mu \mathrm{l}$ Annexin V-FITC $(20 \mu \mathrm{g} / \mathrm{ml})$ and $5 \mu \mathrm{l}$ propidium iodide (PI; $50 \mu \mathrm{g} / \mathrm{ml}$ ) (BD Biosciences, Franklin Lakes, NJ, USA). Following a 15-min incubation at room temperature in the dark, the apoptotic rate was analyzed using a flow cytometer (FC500; Beckman Coulter, Inc., Brea, CA, USA).

Detection of ROS. Following treatment with GFPs for $12 \mathrm{~h}$ at concentrations of 50 and $200 \mu \mathrm{g} / \mathrm{ml}$, the cells were suspended and incubated with $10 \mu \mathrm{M}$ dichlorodihydrofluorescein diacetate (DCFH-DA) for $10 \mathrm{~min}$ at $37^{\circ} \mathrm{C}$ in the dark. After being washed with PBS 3 times, the intracellular ROS levels were determined using a flow cytometer (FC500; Beckman Coulter).

Detection of MMP. The cells were seeded into 6-well plates at $5 \times 10^{4} /$ well and treated with 50 and $200 \mu \mathrm{g} / \mathrm{ml} \mathrm{GFPs}$ for $12 \mathrm{~h}$. The cells were further incubated with $2 \mu \mathrm{M} 5,5^{\prime}, 6,6$ '-tetrachloro-1,1',3,3'-tetraethylbenzimidazolylcarbocyanine iodide (JC-1; Sigma-Aldrich) at $37^{\circ} \mathrm{C}$ for $10 \mathrm{~min}$. After being washed with PBS, the changes in fluorescent color were examined using a fluorescence microscope (x20 magnification; CCD camera, TE2000; Nikon, Tokyo, Japan).

MCF-7 tumor xenograft model. Six-week-old male BALB/c nude mice purchased from Weitong Lihua Laboratory Animal Technology Ltd. Co. (Beijing, China) were used in our in vivo experiments. The protocol was approved by the Animal Ethics Committee of Jilin University. The mice were housed in groups 3 per cage and maintained on a $12 \mathrm{~h}$ light/dark cycle at $23 \pm 1^{\circ} \mathrm{C}$ with water and food available ad libitum.

An amount of $0.1 \mathrm{ml}\left(1 \times 10^{8}\right.$ cells $\left./ \mathrm{ml}\right)$ of MCF-7 cells at the mid-log phase was inoculated subcutaneously into the right flank of $\mathrm{BALB} / \mathrm{c}$ nude mice. When the diameter of the tumor reached to $3-5 \mathrm{~mm}$, the mice were divided into 2 groups ( $\mathrm{n}=3$ each) randomly, and orally treated with $0.5 \mathrm{~g} / \mathrm{kg}$ GFPs or DD water every other day continuously for 2 weeks. During the GFP administration, the body weight and tumor dimension were measured. The equation of length $\mathrm{x}$ (width) ${ }^{2} \mathrm{x} 0.5$ was applied to estimate the tumor volume $\left(\mathrm{mm}^{3}\right)$. All the mice were sacrificed via an injection of $200 \mathrm{mg} / \mathrm{kg}$ pentobarbital after the final treatment, and tumor tissues were dissected.

Western blot analysis. The MCF-7 or MDA-MB-231 ( $2 \times 10^{5}$ cells) were seeded into 6-well plates and exposed vaqrious concentrations of GFPs for the indicated periods of time. The cells and collected tumor tissues were lysed by RIPA buffer containing $1 \%$ protease inhibitor cocktail and $2 \%$ phenylmethanesulfonyl fluoride (PMSF) (both from Sigma-Aldrich). The bicinchoninic acid method was applied to detect the protein concentrations. Protein samples $(40 \mu \mathrm{g})$ were separated on a $12 \%$ SDS-PAGE gel, 

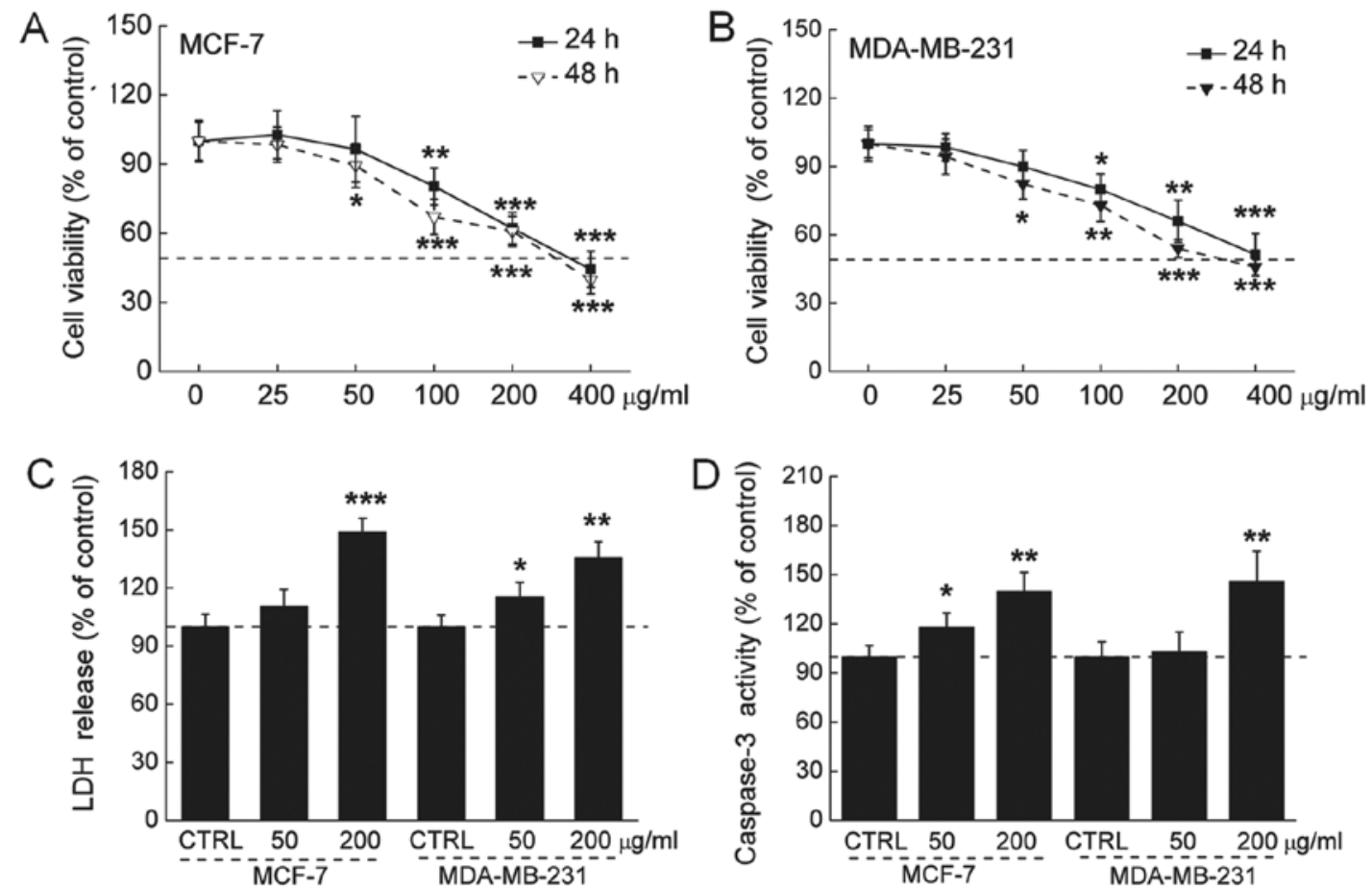

Figure 1. Grifola frondosa polysaccharides (GFPs) exhibit intracellular toxicity in MDA-MB-231 and MCF-7 cells. GFPs dose- and time-dependently suppressed cell viability after 24 and $48 \mathrm{~h}$ of incubation with the (A) MCF-7 and (B) MDA-MB-231. (C) In breast cancer cells, a incubation with the GFPs for $24 \mathrm{~h}$ enhanced LDH release and (D) caspase-3 activation. Data are expressed as the means \pm SD ( $\mathrm{n}=6$ repeats in each group) and analyzed using a one-way ANOVA. ${ }^{*} \mathrm{P}<0.05,{ }^{* *} \mathrm{P}<0.01$ and ${ }^{* * *} \mathrm{P}<0.001$ vs. controls.

and then electroblotted onto nitrocellulose membranes $(0.45 \mu \mathrm{m}$; Bio Basic, Inc., Markham, ON, Canada). The membranes were incubated at $4^{\circ} \mathrm{C}$ overnight with Bcl-2 (MABC573), Bcl-extra large (Bcl-xL; MAB4625), Bax (AB2915), cleaved caspase-3 (AB3623), cleaved caspase-8 (AB1879), and phosphorylated (p)-AKT (05-1003) (all from Merck Millipore, Darmstadt, Germany), total (t)-AKT (ab126811) and p-glycogen synthase kinase-3 $\beta$ (GSK-3 $\beta$ ) (ab75745) (both from Abcam, Cambrige, UK), T-GSK-3 $\beta$ (PK1111) and glyceraldehyde 3-phosphate dehydrogenase (GAPDH) (ABS16) (both from Merck Millipore) at dilution of 1:1,000. The membranes were then incubated with horseradish peroxidase-conjugated secondary antibody (Santa Cruz Biotechnology, Inc., Santa Cruz, CA, USA) for $2 \mathrm{~h}$ at room temperature. Band detection was performed using enhanced chemiluminescence (ECL) detection kits (GE Healthcare Life Sciences, Chalfont, UK). The intensity of the bands was quantified using ImageJ software.

Statistical analysis. Data are expressed as the means \pm standard deviation (SD) and analyzed by a one-way analysis of variance (ANOVA) followed with Dunn's test using SPSS software (SPSS, Inc., Chicago, IL, USA). The $\mathrm{IC}_{50}$ values are calculated using SPSS 16.0 software (IBM Corporation, Armonk, NY, USA). A value $\mathrm{P}<0.05$ was considered to indicate a statistically significant difference.

\section{Results}

Intracellular toxic effects of GFPs on breast cancer cells. The 24-h $\mathrm{IC}_{50}$ values of the GFPs were 335 and $412 \mu \mathrm{g} / \mathrm{ml}$, and the $48-\mathrm{h} \mathrm{IC}_{50}$ values of the GFPs were 295 and $348 \mu \mathrm{g} / \mathrm{ml}$ in the
MCF-7 and MDA-MB-231 cells, respectively (Fig. 1A and B). The release of LDH was increased during cell death. An approximately 47 and $32 \%$ LDH over-release was observed in the $200 \mu \mathrm{g} /$ ml GFP-treated MCF-7 and MDA-MB-231 cells $(\mathrm{P}<0.01$; Fig. 1C). The activation of caspase-3 serves as a marker of cell apoptosis. We found that the GFPs at $200 \mu \mathrm{g} / \mathrm{ml}$ enhanced caspase- 3 activation by almost 35 and $43 \%$ in the MCF-7 and MDA-MB-231 cells, respectively ( $\mathrm{P}<0.01$; Fig. 1D).

In addition, incubation with the GFPs $(50 \mu \mathrm{g} / \mathrm{ml})$ for $12 \mathrm{~h}$ led to approximately 22 and $21 \%$ of the MCF-7 and MDA-MB231 cells, respectively to become apoptotic (Fig. 2A). Furthermore, oxidative stress, particularly, the overproduction of intracellular ROS, leads to cellular dysfunction and apoptosis (19). In this study, following incubation with the GFPs for $12 \mathrm{~h}$ at $200 \mu \mathrm{g} / \mathrm{ml}$, a 50 and $26 \%$ increment in intracellular ROS levels was noted in the MCF-7 and MDA-MB-231 cells, respectively compared with the controls (Fig. 2B). All these data confirmed that GFPs exerted cytotoxic effects on the MCF-7 and MDA-MB-231 cells.

GFPs cause mitochondrial dysfunction. Mitochondrial function plays a central role during cell apoptosis (20). As indicated by the reduced ratio of red to green fluorescence by JC-1 staining, treatment with the GFPs for $12 \mathrm{~h}$ at concentrations of 50 and $200 \mu \mathrm{g} / \mathrm{ml}$ significantly decreased MMP in the MCF-7 and MDA-MB-231 cells, compared with untreated cells (Fig. 3A). Furthermore, the increased expression levels of Bax, cleaved caspase- 3 and caspase-8, and the reduced levels of Bcl-2 and Bcl-xL were observed in the MCF-7 and MDA-MB-231 cells following incubation with the GFPs for $24 \mathrm{~h}$ GFPs at concentrations of 50 and $200 \mu \mathrm{g} / \mathrm{ml}$ (Fig. 3B). 

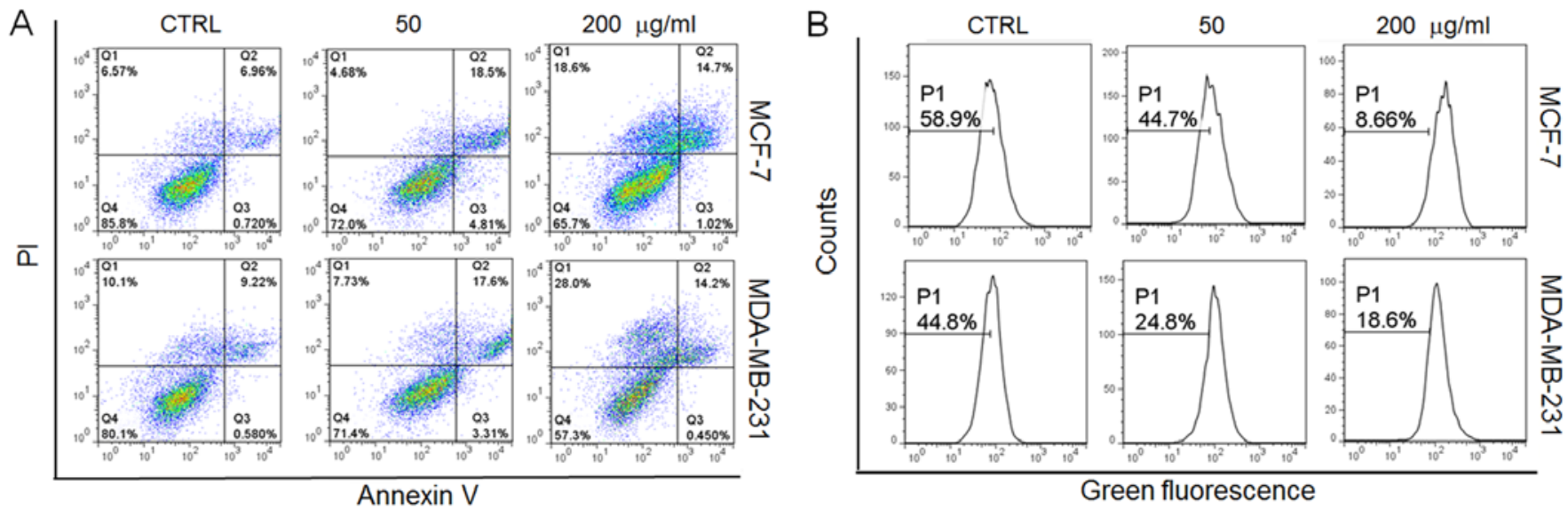

Green fluorescence

Figure 2. Incubation for $12 \mathrm{~h}$ with Grifola frondosa polysaccharides (GFPs) at concentrations of 50 and $200 \mu \mathrm{g} / \mathrm{ml}$ strongly enhanced the (A) apoptotic rate and (B) intracellular reactive oxygen species (ROS) levels in MDA-MB-231 and MCF-7 cells. The experiments were repeated 3 times.
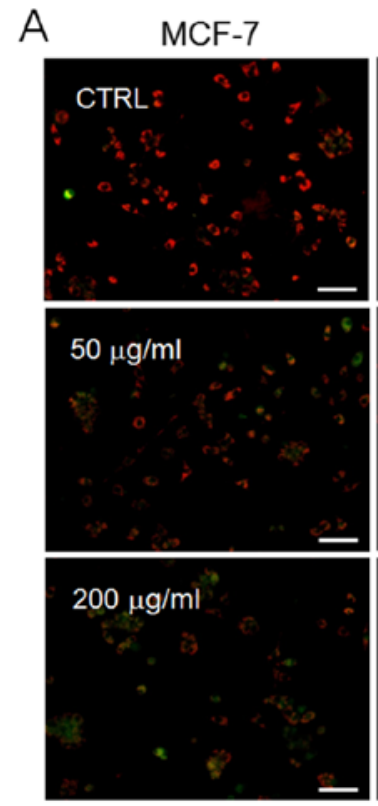

MDA-MB-231
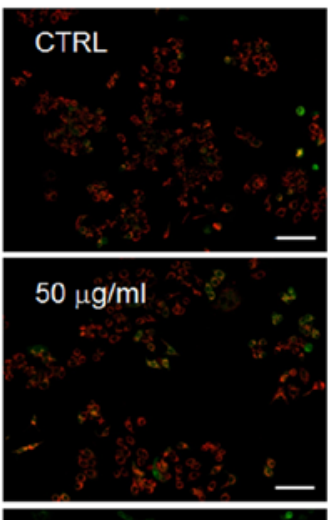

$200 \mu \mathrm{g} / \mathrm{ml}$

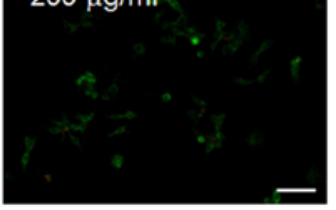

$B$
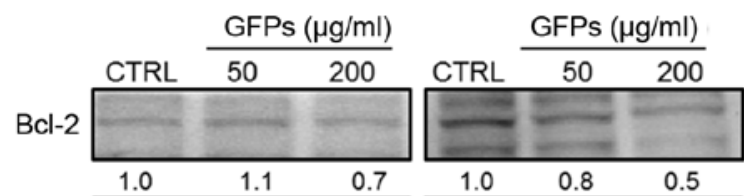

$\mathrm{BCl}-\mathrm{xL}$
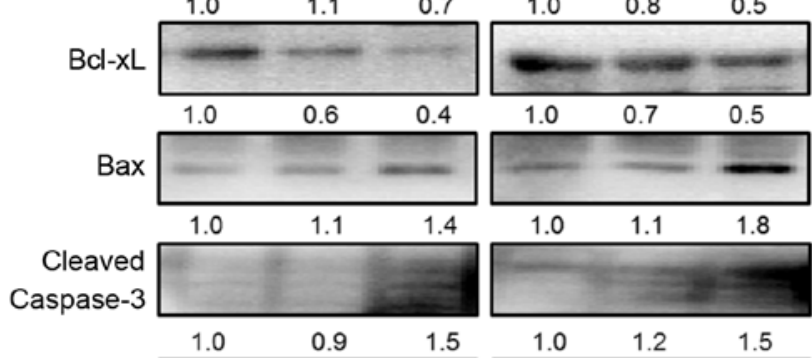

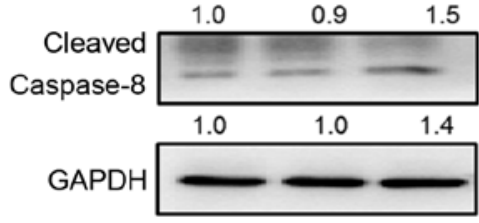

MCF-7

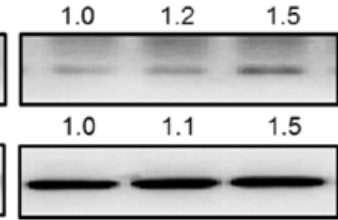

MDA-MB-231

Figure 3. A 12-h incubation with Grifola frondosa polysaccharides (GFPs) at concentrations of 50 and $200 \mu \mathrm{g} / \mathrm{ml}$ caused mitochondrial dysfunction in MDA-MB-231 and MCF-7 cells. (A) The dissipation of $\Delta \Psi \mathrm{m}$ was observed detecting by JC-1 staining (x10 magnification; scale bar, $100 \mu \mathrm{m}$ ). The experiment were repeated 3 times. (B) GFPs dose-dependently reduced the expression of B-cell lymphoma 2 (Bcl-2) and Bcl-extra large (Bcl-xL), and enhanced the levels of Bax, cleaved caspase- 3 and caspase- 8 . The average fold of band intensity compared to related controls was marked respectively ( $\mathrm{n}=6$ repeats in each group).

The activation of $A K T / G S K-3 \beta$ and ERK is involved in GFP-mediated cytotoxicity in breast cancer cells. It has been reported that the activation of AKT/GSK-3 $\beta$ and ERK participate in cell proliferation, survival and even apoptosis $(21,22)$. The GFPs time-dependently suppressed the phosphorylation of AKT and GSK-3 $\beta$ from 0.5 to $3 \mathrm{~h}$ in the breast cancer cells incubated with $200 \mu \mathrm{g} / \mathrm{ml}$ of GFPs, particularly at 1 and $3 \mathrm{~h}$ (Fig. 4). In addition, incubation with $200 \mu \mathrm{g} / \mathrm{ml} \mathrm{GFPs}$ significantly inhibited the activation of ERK from 1 and $3 \mathrm{~h}$ in the MCF-7 and MDA-MB-231 cells (Fig. 4).

GFPs inhibits the growth of MCF-7 tumor xenografts. GFP administration at $0.5 \mathrm{~g} / \mathrm{kg}$ significantly suppressed the growth of MCF-7 tumor xenografts from the 8th day to the end of the experiment $(\mathrm{P}<0.05$; Fig. $5 \mathrm{~A}$ and $\mathrm{C})$. Compared with the controls, GFPs decreased the tumor size by almost $42 \%$ on the 14th day ( $\mathrm{P}<0.01$; Fig. 5C). The GFPs did not to influence the body weight of the mice compared with the untreated mice, which suggested limited aggressive side-effects (Fig. 5B). Additionally, compared with the controls, in the tumor tissues from the treated mice, GFPs increased the expression levels of Bax, cleaved caspase- 3 and caspase- 8 , and suppressed the expression levels of Bcl-2 and Bcl-xL (Fig. 5D).

\section{Discussion}

In the present study, the potential anti-tumor effects of GPFs on breast cancer were successfully confirmed in MCF-7 and MDA-MB-231 cells, and tumor-bearing nude mice. The GFPs exerted cytotoxic effects on the breast cancer cell lines, as evidenced by a decrease in cell viability, and an increase in LDH release, ROS accumulation and caspase- 3 activation, as 


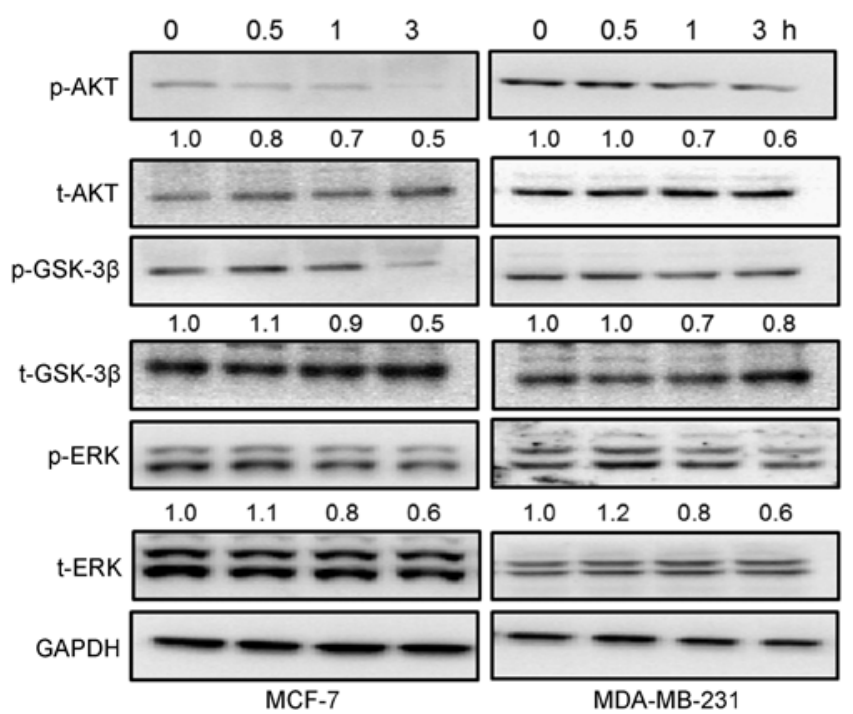

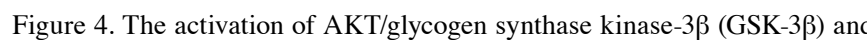
extracellular signal-regulated kinase (ERK) contributes to Grifola frondosa polysaccharide (GFP)-mediated apoptotic cell death. GFPs $(200 \mu \mathrm{g} / \mathrm{ml})$ reduced the expression levels of phosphorylated (p)-AKT, p-GSK-3 $\beta$ and p-ERK from 0.5 to $3 \mathrm{~h}$. The average fold of band intensity compared to the related controls was marked respectively ( $\mathrm{n}=6$ repeats in each group). well as the induction of cell apoptosis and mitochondrial apoptotic alterations. The suppressed phosphorylation of AKT/ GSk-3 $\beta$ and ERK, related to mitochondrial function, revealed the possible mechanisms involved.

During apoptosis, which is a physiological suicide process, mitochondrial function plays a central role (23). The functional loss of the mitochondria is related to the dissipation of MMP (20), which was noted in this study following incubation with the GFPs for $12 \mathrm{~h}$. The reduced Bcl-2 and Bcl-xL levels, and enhanced Bax expression levels were also observed in the GFP-treated cells. The Bcl-2 family, located in the outer mitochondrial membrane, serves as an important index in mitochondrial-mediated apoptosis (24). Moreover, in this study, the accumulation of intracellular ROS was observed in the cells treated with the GFPs. The overproduction of ROS causes oxidative stress, further resulting in mitochondrial apoptosis and cellular dysfunction. It has been reported that ROS accumulation is responsible for the opening mitochondrial permeability transition pore (mPTP), which leads to mitochondrial depolarization, matrix solutes loss and Cyto $c$ release (25). Taken together, the effects of GFPs on mitochondrial function are involved in its anti-breast cancer effects.
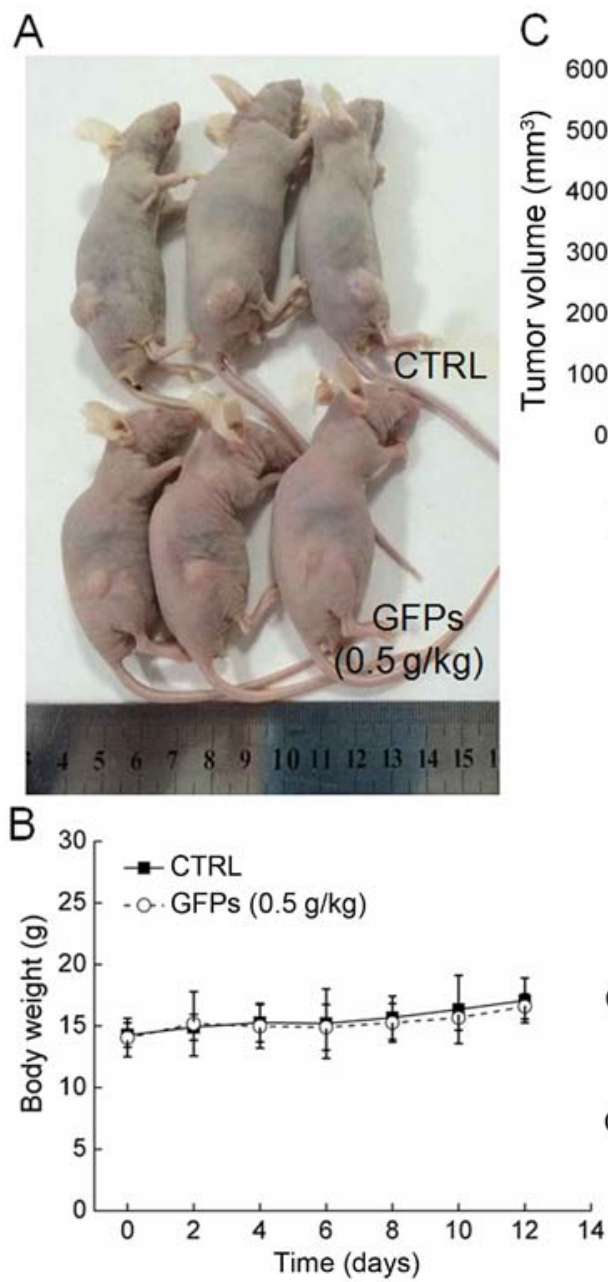

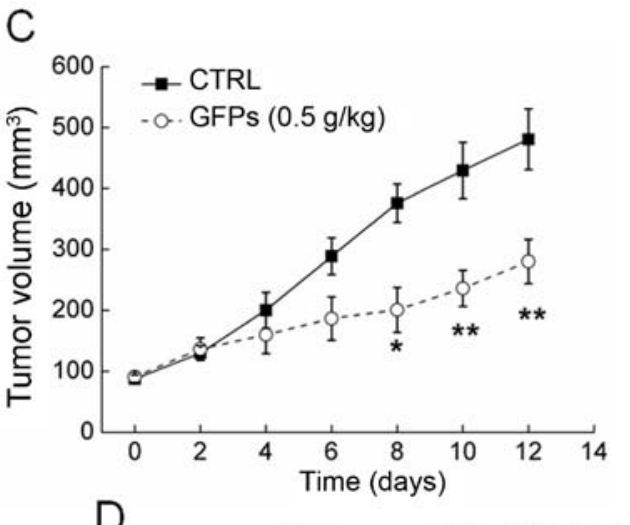

D
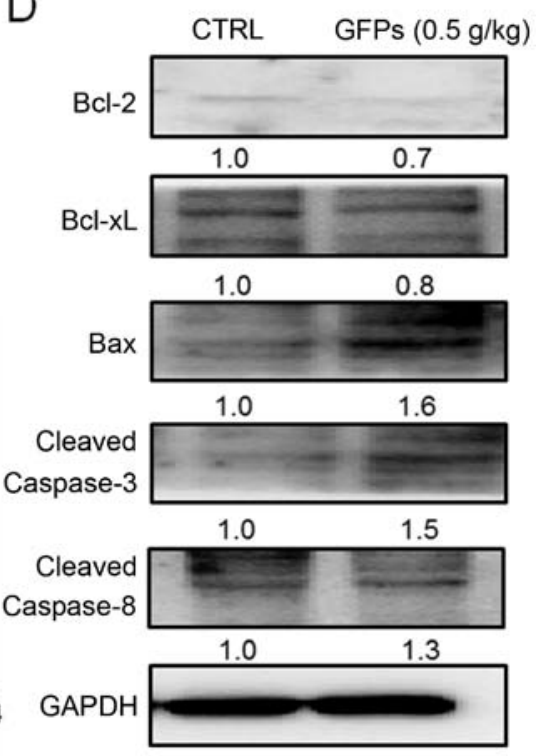

Figure 5. Grifola frondosa polysaccharides (GFPs) suppress the growth of MCF-7 tumor xenografts in nude mice. Male BALB/c athymic nude mice bearing MCF-7 tumors were treated for 14 days. (A) MCF-7 tumor xenograft growth between GFP-treated and untreated nude mice. (B) GFPs exerted no significant effects on body weight among the experimental mice. (C) Growth curves of MCF-7 tumor xenografts in GFP-treated and untreated mice. Tumor sizes were measured every 2 days. Data are expressed as the means \pm SD $(n=3)$ and analyzed using a one-way ANOVA. ${ }^{*}<0.05$ and ${ }^{* *} \mathrm{P}<0.01$ vs. controls. (D) GFPs downregulated the anti-apoptotic proteins and upregulated the pro-apoptotic proteins in tumor tissues from treated mice. The average fold of band intensity compared with the untreated mice was marked respectively $(n=3)$. 
On the other hand, mitochondria control the intrinsic pathway of apoptosis, and during this process, MMP ignites caspases and other catabolic enzyme activation (26). Caspases are considered as inactive pro-enzymes and will be activated via proteolytic cleavage (27). Caspase-8, located mostly in the mitochondria, undergoes dimerization, and then cleaves itself to its fully activated form (28), which further leads to the cleavages of effector caspases in the cytosol (caspase-3) (29). Caspase-3, amplifying the initiation signals from caspase-8, plays a central role in activating the apoptotic program via regulating other caspases and some vital proteins (30), and it is important for cell death in a tissue-, cell type- or death stimulus-specific manner (31). In this study, in MCF-7 and MDA-MB-231 cells, and MCF-7 tumor xenografts, GFPs significantly enhanced the expressions of cleaved caspase-3 and caspase- 8 , which revealed that the anticancer activity of GFPs was associated with the regulation on caspase activation, which further targets the mitochondria.

AKT signaling is responsible for cell proliferation and apoptosis, which regulates apoptotic proteins including $\mathrm{Bcl}-2$ family members GSK-3 $\beta$ (21). The reduced phosphorylation of AKT activates its downstream GSK-3 $\beta$, which promotes Bax activation (32). As previously reported, GSK-3 $\beta$ mediates the release of cytochrome $c$ into the cytosol, and its activated form helps to open mPTP (33). Via the AKT/ GSK-3 $\beta$ - and ROS-dependent mitochondrial-mediated pathway, $18 \beta$-glycyrrhetinic acid induces the apoptosis of pituitary adenoma cells (23). Furthermore, the ERK pathway has been reported to be a target for cancer therapy, which is hyper-acted in human tumors $(34,35)$. p-ERK, an active form, inhibits pro-apoptotic signals via the modulation of numerous substrates (22). In our study, the GFPs strongly suppressed the phosphorylation of AKT/GSK-3 $\beta$ and ERK in the MCF-7 and MDA-MB-231 cells, and this suppression may be involved in the GFP-mediated anti-tumor effects. Furthermore, ERK has been shown to exert positive regulatory effects on Bcl-2 and $\mathrm{Bcl}-\mathrm{xL}$ expression, and ERKs/Bcl-2 have been confirmed as potential targets for cancer cell apoptosis $(36,37)$. Previous studies have indicated that AKT contributes to the maintenance of mitochondrial integrity, which also affects Bcl-2 expression $(38,39)$. Collectively, the downregulation of AKT/ GSK-3 $\beta$ and ERK activation contributes to GFP-induced mitochondrial apoptosis.

The anti-breast cancer effects of GFPs were successfully confirmed in in vitro and in vivo experiments. GFPs reduced cell viability, enhanced the apoptotic rate, increased the ROS and caspase-3 intracellular levels, and caused LDH over-release, as well as MMP dissipation and the abnormal expression of pro-apoptotic proteins. The suppressed activation of ERK and AKT/GSK-3 $\beta$ in the GFP-incubated cells was responsible for mitochondrial dysfunction. All these findings reveal that the mitochondrial-dependent apoptotic pathway contributes to GFP-induced cytotoxicity in the MCF-7 and MDA-MB-231 cells, which provides pharmacological evidence to support the use of GFPs as a potential chemotherapeutic agent.

\section{Acknowledgements}

This study was supported by Jilin Province Science and Technology Key Problem of China (2014020314YY).

\section{References}

1. Jemal A, Bray F, Center MM, Ferlay J, Ward E and Forman D: Global cancer statistics. CA Cancer J Clin 61: 69-90, 2011.

2. Hosseini BA, Pasdaran A, Kazemi T, Shanehbandi D, Karami H, Orangi $\mathrm{M}$ and Baradaran B: Dichloromethane fractions of Scrophularia oxysepala extract induce apoptosis in MCF-7 human breast cancer cells. Bosn J Basic Med Sci 15: 26-32, 2015.

3. Chang $\mathrm{CH}$, Chen SJ and Liu CY: Adjuvant treatments of breast cancer increase the risk of depressive disorders: a population-based study. J Affect Disord 182: 44-49, 2015.

4. Vadodkar AS, Suman S, Lakshmanaswamy R and Damodaran C: Chemoprevention of breast cancer by dietary compounds. Anticancer Agents Med Chem 12: 1185-1202, 2012.

5. Jin CY, Kim GY and Choi YH: Induction of apoptosis by aqueous extract of Cordyceps militaris through activation of caspases and inactivation of Akt in human breast cancer MDA-MB-231 cells. J Microbiol Biotechnol 18: 1997-2003, 2008.

6. Yoo HS, Shin JW, Cho JH, Son CG, Lee YW, Park SY and Cho CK: Effects of Cordyceps militaris extract on angiogenesis and tumor growth. Acta Pharmacol Sin 25: 657-665, 2004.

7. Ohno N, Suzuki I, Oikawa S, Sato K, Miyazaki T and Yadomae T: Antitumor activity and structural characterization of glucans extracted from cultured fruit bodies of Grifola frondosa. Chem Pharm Bull (Tokyo) 32: 1142-1151, 1984.

8. Inoue $\mathrm{A}$, Kodama $\mathrm{N}$ and Nanba $\mathrm{H}$ : Effect of maitake (Grifola frondosa) D-fraction on the control of the T lymph node Th-1/Th-2 proportion. Biol Pharm Bull 25: 536-540, 2002.

9. Ma XL, Meng M, Han LR, Li Z, Cao XH and Wang CL: Immunomodulatory activity of macromolecular polysaccharide isolated from Grifola frondosa. Chinese Journal of Natural Medicines 13: 906-914, 2015.

10. Cui FJ, Li Y, Xu YY, Liu ZQ, Huang DM, Zhang ZC and Tao WY: Induction of apoptosis in SGC-7901 cells by polysaccharide-peptide GFPS1b from the cultured mycelia of Grifola frondosa GF9801. Toxicol In Vitro 21: 417-427, 2007.

11. Wang CL, Meng M, Liu SB, Wang LR, Hou LH and Cao XH: A chemically sulfated polysaccharide from Grifola frondos induces HepG2 cell apoptosis by notch1-NF- $\mathrm{B}$ pathway. Carbohydr Polym 95: 282-287, 2013.

12. Nakagawa S, Shiraishi T, Kihara S and Tabuchi K: Detection of DNA strand breaks associated with apoptosis in human brain tumors. Virchows Arch 427: 175-179, 1995.

13. Joselin AP, Schulze-Osthoff K and Schwerk C: Loss of Acinus inhibits oligonucleosomal DNA fragmentation but not chromatin condensation during apoptosis. J Biol Chem 281: 12475-12484, 2006.

14. Chen R, Liu S, Piao F, Wang Z, Qi Y, Li S, Zhang D and Shen J: 2,5-Hexanedione induced apoptosis in mesenchymal stem cells from rat bone marrow via mitochondria-dependent caspase-3 pathway. Ind Health 53: 222-235, 2015.

15. Wang Y, Wu Y, Luo K, Liu Y, Zhou M, Yan S, Shi H and Cai Y: The protective effects of selenium on cadmium-induced oxidative stress and apoptosis via mitochondria pathway in mice kidney. Food Chem Toxicol 58: 61-67, 2013.

16. Hu Q, Wu D, Chen W, Yan Z and Shi Y: Proteolytic processing of the caspase- 9 zymogen is required for apoptosome-mediated activation of caspase-9. J Biol Chem 288: 15142-15147, 2013.

17. Lin YL, Wang GJ, Huang CL, Lee YC, Liao WC, Lai WL, Lin YJ and Huang NK: Ligusticum chuanxiong as a potential neuroprotectant for preventing serum deprivation-induced apoptosis in rat pheochromocytoma cells: functional roles of mitogen-activated protein kinases. J Ethnopharmacol 122: 417-423, 2009.

18. Lou H, Fan P, Perez RG and Lou H: Neuroprotective effects of linarin through activation of the PI3K/Akt pathway in amyloid- $\beta$-induced neuronal cell death. Bioorg Med Chem 19: 4021-4027, 2011.

19. Brown DI and Griendling KK: Regulation of signal transduction by reactive oxygen species in the cardiovascular system. Circ Res 116: 531-549, 2015.

20. Hisatomi T, Ishibashi T, Miller JW and Kroemer G: Pharmacological inhibition of mitochondrial membrane permeabilization for neuroprotection. Exp Neurol 218: 347-352, 2009.

21. Maurer U, Preiss F, Brauns-Schubert P, Schlicher L and Charvet C: GSK-3 - at the crossroads of cell death and survival. J Cell Sci 127: 1369-1378, 2014.

22. Sweatt JD: The neuronal MAP kinase cascade: a biochemical signal integration system subserving synaptic plasticity and memory. J Neurochem 76: 1-10, 2001. 
23. Wang D, Wong HK, Feng YB and Zhang ZJ: 18beta-glycyrrhetinic acid induces apoptosis in pituitary adenoma cells via ROS/MAPKs-mediated pathway. J Neurooncol 116: 221-230, 2014.

24. Chan SL and Yu VC: Proteins of the bcl-2 family in apoptosis signalling: from mechanistic insights to therapeutic opportunities. Clin Exp Pharmacol Physiol 31: 119-128, 2004.

25. Bernardi P and Rasola A: Calcium and cell death: the mitochondrial connection. Subcell Biochem 45: 481-506, 2007.

26. Galluzzi L, Vitale I, Kepp O, Séror C, Hangen E, Perfettini JL, Modjtahedi $\mathrm{N}$ and Kroemer G: Methods to dissect mitochondrial membrane permeabilization in the course of apoptosis. Methods Enzymol 442: 355-374, 2008.

27. Hippe D, Gais A, Gross U and Lüder CG: Modulation of caspase activation by Toxoplasma gondii. Methods Mol Biol 470: 275-288, 2009.

28. Schug ZT, Gonzalvez F, Houtkooper RH, Vaz FM and Gottlieb E: BID is cleaved by caspase- 8 within a native complex on the mitochondrial membrane. Cell Death Differ 18: 538-548, 2011.

29. Lee KH, Feig C, Tchikov V, Schickel R, Hallas C, Schütze S, Peter ME and Chan AC: The role of receptor internalization in CD95 signaling. EMBO J 25: 1009-1023, 2006.

30. Espín R, Roca FJ, Candel S, Sepulcre MP, González-Rosa JM, Alcaraz-Pérez F, Meseguer J, Cayuela ML, Mercader N and Mulero V: TNF receptors regulate vascular homeostasis in zebrafish through a caspase-8, caspase-2 and P53 apoptotic program that bypasses caspase-3. Dis Model Mech 6: 383-396, 2013.

31. Porter AG and Jänicke RU: Emerging roles of caspase-3 in apoptosis. Cell Death Differ 6: 99-104, 1999.

32. Zhang L, Zhang Y and Xing D: LPLI inhibits apoptosis upstream of Bax translocation via a GSK-3beta-inactivation mechanism. J Cell Physiol 224: 218-228, 2010.
33. Petit-Paitel A, Brau F, Cazareth J and Chabry J: Involvment of cytosolic and mitochondrial GSK-3beta in mitochondrial dysfunction and neuronal cell death of MPTP/MPP-treated neurons. PLoS One 4: e5491, 2009.

34. Krajarng A, Nakamura Y, Suksamrarn S and Watanapokasin R: $\alpha$-Mangostin induces apoptosis in human chondrosarcoma cells through downregulation of ERK/JNK and Akt signaling pathway. J Agric Food Chem 59: 5746-5754, 2011.

35. Tada K, Kawahara K, Matsushita S, Hashiguchi T, Maruyama I and Kanekura T: MK615, a Prunus mume Steb. Et Zucc ('Ume') extract, attenuates the growth of A375 melanoma cells by inhibiting the ERK1/2-Id-1 pathway. Phytother Res 26: 833-838, 2012.

36. Zhao Y, Shen S, Guo J, Chen H, Greenblatt DY, Kleeff J, Liao Q, Chen G, Friess $H$ and Leung PS: Mitogen-activated protein kinases and chemoresistance in pancreatic cancer cells. J Surg Res 136: 325-335, 2006

37. Balmanno K and Cook SJ: Tumour cell survival signalling by the ERK1/2 pathway. Cell Death Differ 16: 368-377, 2009.

38. Lim JY, Park SI, Oh JH, Kim SM, Jeong CH, Jun JA, Lee KS, Oh W, Lee JK and Jeun SS: Brain-derived neurotrophic factor stimulates the neural differentiation of human umbilical cord blood-derived mesenchymal stem cells and survival of differentiated cells through MAPK/ERK and PI3K/Akt-dependent signaling pathways. J Neurosci Res 86: 2168-2178, 2008.

39. Ma R, Xiong N, Huang C, Tang Q, Hu B, Xiang J and $\mathrm{Li}$ G: Erythropoietin protects PC12 cells from beta-amyloid(25-35)-induced apoptosis via PI3K/Akt signaling pathway. Neuropharmacology 56: 1027-1034, 2009. 